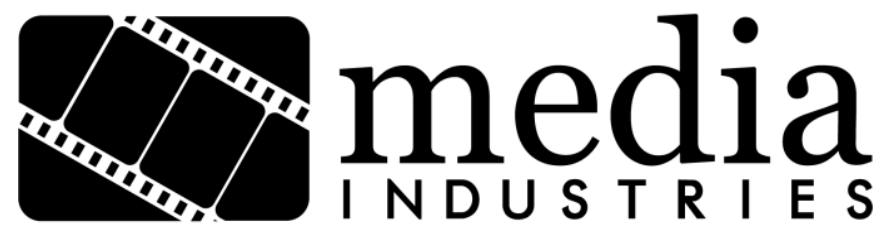

\title{
On Comparison
}

\author{
Nitin Govil ${ }^{1}$ \\ University of Southern California \\ ngovil [AT] usc.edu
}

\begin{abstract}
:
Comparison is a widely used form of analysis that informs methodology and practice in the humanities and social sciences. As an integral part of empirical and interpretive work, comparison is a way to capture differences and represent similarities. As a medium of measurement, comparison regularizes distinction within standard frameworks and ideal types. Comparison has a politics too, clearly visible in the legacy of approaches like area studies. How does comparison function in critical work on the media industries? What is the present state and future of comparison, given the proliferation of alignments between media sectors in global and local contexts? In short, what do we do when we compare media industries? This essay traces the practice, role, and possible future directions of transnational comparison in media industries work, building on a decade-long study of Hollywood and Bombay cinema.
\end{abstract}

Keywords: India, Hollywood, Research Methods, Film, Globalization

We are now at the close of a fascinating century of encounter between Hollywood and Bombay cinema. Throughout this history, the two global media industries have circled each other in a dance of difference and similarity: in one moment, facing each other as Manichean opposites; at another, joined at the hip like kindred formations. Because of this history, it has become somewhat commonplace to claim that Bombay cinema and Hollywood are studies in contrast. Yet contemporary press and trade accounts seem to have boiled down these interindustry encounters to a core budgetary logic.

For example, The Hollywood Reporter recently featured an interview about interindustry relations with one of Hindi cinema's biggest stars, Shahrukh Khan. His recently-released film Chennai Express (2013) is a coproduction between Khan's media company, Red Chillies Entertainment, and Disney-UTV. With its US\$454 million acquisition of the Indian media and entertainment company UTV in 2012, Disney's entry into locally branded Indian film content represents a relatively rare instance of its involvement in non-Hollywood production. Commenting on the Red Chillies and UTV-Disney tie-in, Khan notes that:

I think that it's fantastic that the Hollywood studios are here. At first the studios wanted to popularize Hollywood films here but our cinema is deeply rooted in Indian culture. So it's good to see them producing Indian films. We also learn a 
lot from the experience of working with an international studio ... it's a sign of changing times and will benefit Indian films to go international faster. ${ }^{2}$

Given the recent proliferation of financial alignments between Bombay cinema and Hollywood, global press accounts comparing India and the United States are dominated by stories of rising profits and media mergers. Part of the enthusiasm in such comparisons is that they deal with a perceived inversion of power relations in the international media economy, with Hollywood toppled from its position of global mastery. Not only are affinities between Hollywood and Bombay cinema taken as a sign of Indian media achievement, but these proliferating economic connections also testify to a globally relevant India.

While I acknowledge the realignment of financial arrangements and the social forces that have "reoriented" world trade flows, ${ }^{3}$ I remain skeptical of the economic logic of such contemporary comparisons. As a preliminary attempt at suggesting alternatives, I've thought that rather than taking media industries as predetermined and stable formations, we might think about the provisional forms, sites, and practices that media industries comprise. This would involve thinking about the social, textual, political, and cultural infrastructures and interactions assembled under the semiotic sign of "industry." This would mean that we begin with a dynamic sense of industries as social and textual arrangements, sites of enactment and other dramaturgies of interaction, reflection, and reflexivity. When it comes to Hollywood-Bombay cinema encounters, such a fluid conception of industry might help enliven comparative methods by suggesting that the term industry itself creates a certain frame of reference within which to compare media practices dispersed in space and time. But how can we get around the fact that comparison deals in the "boundary work" of differentiation? In demarcating its object of inquiry, doesn't comparative work simply redraw the lines that figure industry? Before we move along to looking at the possibilities and limits of comparison in greater detail, it might be useful to think broadly about methods and disciplines.

Comparison is a widely used type of scholarly analysis informing methodology, theory, and practice in the humanities and social sciences. Comparison is central to both empirical and interpretive work. As a medium of measurement in both quantitative and qualitative methods, comparison regularizes difference within standard frameworks - in other words, comparison is a form of framing. This suggests stasis, but comparative methods are also dynamic because they organize claims and engage contrasts. At the same time, comparison tends toward objectification by formalizing phenomena in the process of analysis, creating trajectories of proximity and distance, networks of affinity and dissimilarity, and taxonomies of features both shared and exceptional. But comparison is also a tremendously broad enterprise. Susan Friedman has usefully described a number of imperatives to comparison, from the cognitive (comparison is integral to analogical and figural thinking) to the sociocultural (comparison is a way of organizing human behavior and social relations) and the ethicopolitical (comparison can either revivify or reject the "romance" of the universal and the singular). 4

In our field, thinking critically about comparison means that we engage the multiple dimensions of comparativity produced across disciplinary cultures. This means understanding comparison as a kind of "travelling concept," Mieke Bal's term for the movement of meanings between disciplines, scholars, and histories, with "processes of differing assessed before, during, and after each 'trip..$^{\prime \prime \prime}$

Thinking archeologically about media, for example, Katherine Hayles suggests that a comparative media studies can provide a "rubric" for the study of print and digital productions 
in way that is historical, formal, procedural, and material. The multiple ways in which to approach and theorize media transitions help ward off teleologies of technological development. ${ }^{6}$ In a more sociological vein, Daniel Hallin and Paulo Mancini suggest that a comparative approach to media demystifies assumptions about the universality of media practices while making possible certain structural similarities that link media systems to one another. ${ }^{7}$ The focus here is analytic precision in the drawing of models in the generation of concepts and theories in the vein of Weberian ideal types. Both the archeological and sociological approaches to comparative media represented by Hayles, Hallin, and Mancini are united by a project of clarification while preserving the possibilities of more experimental and speculative forms of comparison. Capturing this contradiction with a focus on media structures, Sonia Livingstone calls the comparative study of cross-national media industries an "apparent impossibility and an urgent necessity." 8

Yet, comparison can also breed contempt, especially when one considers this cross-national history and its institutionalization. Postwar intellectual formations like area studies used comparison to justify Cold War mentalities, focusing on the regional and the national as a geopolitical unit. ${ }^{9}$ The institutionalization of comparison in modernization theory forged a policy alignment between university and state interests. Comparison's role in this disciplinary history was to frame the national as an index of psychological, social, and cultural disposition. In this way, the national was a "modular" form, capable of registering difference through a common discourse. 10

Modernization theory activated such national distinctions to organize media industries in hierarchies according to their development. Even in oppositional disciplinary cultures like political economy, which seek to address structural inequalities and the management and redistribution of resources, the national serves as a site to aggregate data and situate power. This national aggregation generates the tropes of economic magnitude that dominate accounts of media transit. After all, despite the rhetoric and texture of media encounter, scholarly legitimacy is often granted only to those comparative accounts that demonstrate definitive, measurable, and spectacular market impact. For example, in his study of the international development of film industries prior to World War II, Gerben Bakker excludes Japanese, Indian, and Hong Kong industries on the grounds that "since 1945 they have become quite successful relative to Europe, but before that they were internationally insignificant." 11 Similarly, Manuel Castells suggests that the Indian film industries have "evolved largely independently from the global network of media networks," and only now, because of state and market subsidy, are more enumerated "structures of collaboration" between Indian and American media industries proliferating. ${ }^{12}$ To follow Bakker's rationalization, we needn't be interested in Hollywood's investment in India, which, in the mid-1990s, made about as much money as it did in Israel and less than it did in Poland. To follow Castells, we should prioritize Hollywood's history in India by focusing on Hollywood's encouragement of recent corporatization initiatives in Indian film. Yet, for all their analytical clarity, approaches taken by Bakker and Castells risk missing the ephemeral points of contact that seep into and slip beyond official histories and formal political economies.

Comparison remains a vital and energetic way to study media industries in global and local contexts. For those of us interested in working on media industries, our task is not to refuse comparison but to compare differently: to figure a politics and practice of relation that is transformative rather than taxonomic. In this way, we might gesture beyond comparison to what Rey Chow calls "entanglement," encounters figured "through disparity rather than 
equivalence." By disrupting frames of classification, entanglements signal a "derangement in the organization of knowledge caused by unprecedented adjacency and comparability or parity."13

Of course, we must account for the cultural forms that organize media industries in different ways. ${ }^{14}$ But we must also understand industry comparisons in terms of the "occasions" toward which they are oriented and intended. ${ }^{15}$ In addition to this "occasionality" of comparison, we might also - to follow Rita Felski and Susan Friedman's formulation - engage media industries as "agents as well as objects of comparison." 16 If media industries are "forms of comparative thinking," then perhaps comparison is at the root of their materiality as well as our scholarship.

1 Nitin Govil is Assistant Professor of Critical Studies in the School of Cinematic Arts at the University of Southern California. He is a coauthor of Global Hollywood and Global Hollywood 2 and has authored essays in over twenty journals and anthologies. His work has been translated into Chinese, Portuguese, Spanish, and Turkish. He is currently completing two new book projects: the first is The Indian Film Industry, coauthored with Ranjani Mazumdar; the second is a book on a century of film culture between Hollywood and Bombay called Orienting Industry, forthcoming from New York University Press.

${ }^{2}$ Quoted in Nyay Bhushan, "Bollywood Star Shah Rukh Khan: 'It's Good to See Hollywood Producing Films,'” Hollywood Reporter, July 26, 2013.

3 See Andre Gunder Frank, ReOrient: Global Economy in the Asian Age (Berkeley: University of California Press, 1998) and Michael Curtin and Hemant Shah, eds., Reorienting Global Communication: Indian and Chinese Media beyond Borders (UrbanaChampaign: University of Illinois Press, 2010).

4 Susan Stanford Friedman, "Why Not Compare?" PMLA 126, no. 3 (2011): 753-62.

5 Mieke Bal, Traveling Concepts in the Humanities: A Rough Guide (Toronto: University of Toronto Press, 2002), 24.

${ }^{6}$ N. Katherine Hayles, How We Think: Digital Media and Contemporary Technogenesis (Chicago: University of Chicago Press, 2012).

7 Daniel C. Hallin and Paolo Mancini, Comparative Media Systems: Three Models of Media and Politics (New York: Cambridge University Press, 2004).

8 Sonia Livingstone, "On the Challenges of Cross-National Comparative Media Research," European Journal of Communication 18, no. 4 (2003): 477-500.

9 For an assessment of this history and the possibilities of recuperation in the work of comparative scholars like Benedict Anderson, see H. D. Harootunian, "Ghostly Comparisons: Anderson's Telescope," Diacritics 29, no. 4 (1999): 135-49.

${ }^{10}$ For a critique of the "modular" form of the national, see Partha Chatterjee, Nationalist Thought and the Colonial World: A Derivative Discourse (Tokyo: Zed Books, 1986). For a sense of how these modular forms have been "refortified" under contemporary neoliberal regimes, see Manu Goswami, "Rethinking the Modular Form: Toward a Sociohistorical Conception of Nationalism," Comparative Studies in Society and History 44, no. 4 (2002): 770-99.

${ }^{11}$ Gerben Bakker, Entertainment Industrialized: The Emergence of the International Film Industry, 1890-1940 (Cambridge: Cambridge University Press, 2008), 4.

12 Manuel Castells, Communication Power (New York: Oxford University Press, 2009), 92. 
${ }^{13}$ Rey Chow, Entanglements, or Transmedial Thinking of Capture (Durham, NC: Duke University Press, 2012), 11.

${ }^{14}$ Paul Willemen, "For a Comparative Film Studies," Inter-Asia Cultural Studies 6, no. 1 (2005): 103.

${ }^{15}$ For more on the concepts of "occasion" and "occasionality," rooted in arts and aesthetics, see Hans-Georg Gadamer, Truth and Method, trans. Joel Weinsheimer and Donald G. Marshall (London: Bloomsbury, 1989). For an extension of "occasion" into novelistic genres and the literary marketplace-what he calls "the practical circumstances governing the composition and reception of a piece of speech or writing" - see Ian Hunter, "Providence and Profit: Speculations in the Genre Market," Southern Review 22, no. 3 (1989): 211-23. Similarly, in his discussion of media texts and spectators, Toby Miller suggests that occasionality "details the conditions under which a text is made, circulated, received, interpreted, and criticized . . . a life remade again and again by institutions, discourses, and practices of distribution and reception." See Toby Miller and Robert Stam, A Companion to Film Theory (Malden, MA: Blackwell, 1999), 4.

${ }^{16}$ Rita Felski and Susan Friedman, "Introduction," New Literary History 40, no. 3 (2009): v-ix.

\section{Bibliography}

Bakker, Gerben. Entertainment Industrialized: The Emergence of the International Film Industry, 1890-1940. Cambridge: Cambridge University Press, 2008.

Bal, Mieke. Traveling Concepts in the Humanities: A Rough Guide. Toronto: University of Toronto Press, 2002.

Bhushan, Nyay. “Bollywood Star Shah Rukh Khan: 'It's Good to See Hollywood Producing Films.'" Hollywood Reporter, July 26, 2013.

Castells, Manuel. Communication Power. New York: Oxford University Press, 2009.

Chatterjee, Partha. Nationalist Thought and the Colonial World: A Derivative Discourse. Tokyo: Zed Books, 1986.

Chow, Rey. Entanglements, or Transmedial Thinking of Capture. Durham, NC: Duke University Press, 2012.

Curtin, Michael, and Hemant Shah, eds. Reorienting Global Communication: Indian and Chinese Media Beyond Borders. Urbana-Champaign: University of Illinois Press, 2010.

Felski, Rita, and Susan Friedman. "Introduction.” New Literary History 40, no. 3 (2009): v-ix.

Frank, Andre Gunder. ReOrient: Global Economy in the Asian Age. Berkeley: University of California Press, 1998.

Friedman, Susan Stanford. “Why Not Compare?” PMLA 126, no. 3 (2011): 753-62.

Gadamer, Hans-Georg. Truth and Method. Translated by Joel Weinsheimer and Donald G. Marshall. London: Bloomsbury, 1989. 
Goswami, Manu. "Rethinking the Modular Form: Toward a Sociohistorical Conception of Nationalism." Comparative Studies in Society and History 44, no. 4 (2002): 770-99.

Hallin, Daniel C., and Paolo Mancini. Comparative Media Systems: Three Models of Media and Politics. New York: Cambridge University Press, 2004.

Harootunian, H. D. “Ghostly Comparisons: Anderson's Telescope," Diacritics 29, no. 4 ( 1999): 135-49.

Hayles, N. Katherine. How We Think: Digital Media and Contemporary Technogenesis. Chicago: University of Chicago Press, 2012.

Hunter, Ian. "Providence and Profit: Speculations in the Genre Market." Southern Review 22, no. 3 (1989): 211-23.

Livingstone, Sonia. "On the Challenges of Cross-National Comparative Media Research." European Journal of Communication 18, no. 4 (2003): 477-500.

Miller, Toby, and Robert Stam. A Companion to Film Theory. Malden, MA: Blackwell, 1999.

Willemen, Paul. “For a Comparative Film Studies." Inter-Asia Cultural Studies 6, no. 1 (2005): 98112.

\section{(cc) BY-Ne-ND}

Copyright (C) 2015 (Nitin Govil). Media Industries is an open-access, peer-reviewed, online academic journal. As such, we aim to participate in the open exchange of information. This work is licensed under a Creative Commons Attribution Noncommercial No Derivatives (by-nc-nd) License. Under this license, this work is available for sharing and noncommercial distribution provided the appropriate attribution is given. 